Proceedings

\title{
Trends in COVID-19 and School Related Inquries Using 311 NYC Open Data
}

\author{
Adriana Eugene, Naomi Alpert, Wil Lieberman-Cribbin, Emanuela Taioli *
}

Icahn School of Medicine at Mount Sinai

* $\quad$ corresponding: adriana.eugene@mountsinai.org

\begin{abstract}
On March 12 ${ }^{\text {th }}$, New York governor declared a state of emergency, which banned large gatherings, resulting in statewide school and business closures. By November 2020, there were 270,000 confirmed cases of COVID-19 in New York City (NYC). As state-wide lockdown orders were progressively lifted and NYC began to reopen in phases, there was widespread health and safety concerns especially in the reopening of NYC schools. Here we analyzed NYC 311 Call Center Inquiries to assess what types of information NYC residents are seeking in regards to schools during COVID-19. Inquiries from July 7-November 22 that contained the term "School" were downloaded from the NYC Open Data website for 2018(n=32,836), $2019(\mathrm{n}=30,626)$ and 2020(n=45,602). Schoolrelated inquires increased by 39\% from 2018-2020. During 2020, the most common $(49 \%, n=22,471)$ call description was "Coronavirus (COVID-19) and Schools". This tag describes calls seeking information about learning options, school health and safety, and resources for students during the COVID-19 pandemic. Spikes in the volume of these inquiries corresponded to dates when announcements about lock-downs were made by NY public officials. On August $7^{\text {th }}$, the Governor announced schools would reopen during the fall; a spike in "COVID-19 and School" related 311 calls occurred between August 31 $1^{\text {st }}(n=678)$ and September $1^{\text {st }}(n=624)$. A second spike occurred between September $16^{\text {th }}(n=1,043)$ and $17^{\text {th }}(n=713)$ when the mayor announced the school reopening schedule and staffing plan, followed by a spike on September $21^{\text {st }}(n=680)$ when pre-K and special needs classes began in-person learning. This study demonstrates that as NYC residents received school-related news centered around COVID-19, there were increased health and safety concerns. Future announcements about schools plans during COVID-19 need to be conveyed clearly and disseminated effectively in order to avoid confusion about NYC's strategy and address concerns regarding the health and safety around school openings.
\end{abstract}

Keywords: COVID-19; public schools; information seeking behavior; informational database; New York City; school openings

Publisher's Note: MDPI stays neu-

tral with regard to jurisdictional

claims in published maps and insti-

tutional affiliations.

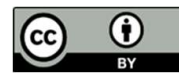

Copyright: (c) 2020 by the authors. Submitted for possible open access publication under the terms and conditions of the Creative Commons Attribution (CC BY) license (http://creativecommons.org/licenses /by/4.0/). 